\title{
Analisis Pengelolaan Obat Pasien BPJS Di Instalasi Farmasi Rumah Sakit Panti Wilasa Citarum Semarang
}

\author{
Devina Eirene Mendrofa ${ }^{1}$, Chriswardani Suryawati ${ }^{2}$ \\ 1) RS Panti Wilasa Citarum, Jl. Citarum 98 Semarang, email : email.iwen@gmail.com \\ 2) Magister Ilmu Kesehatan Masyarakat, Universitas Diponegoro, Semarang
}

Title : Drug Management Analysis of BPJS

Patient in Pharmacy Installation Panti Wilasa Citarum Hospital Semarang

\begin{abstract}
Abstrak
Bertambah banyaknya pasien BPJS menyebabkan rumah sakit harus mengatur efisiensi pengeluaran untuk pasien BPJS agar keuangan rumah sakit dapat berjalan dengan baik. Pengelolaan obat BPJS di Instalasi Farmasi Rumah Sakit Panti Wilasa Citarum mengalami kendala sehingga perlu dianalisa penyebab permasalahan pengelolaan obat BPJS dan bagaimana kebijakan rumah sakit dalam mengatasi permasalahan pengelolaan obat pasein sehingga penggeluaran biaya pasien BPJS tidak membengkak.
\end{abstract}

Penelitian ini merupakan penelitian kualitatif dengan subjek penelitian 1 direksi, 1 kepala instalasi farmasi, 1 petugas gudang, 1 tim verifikator, dan 4 orang orang petugas farmasi. Variabel penelitian ini adalah perencanaan obat, pengadaan obat, pendistribusian obat, pengendalian obat dan kebijakan rumah sakit. Analisis data yang digunakan content analysis yaitu pengumpulan data, reduksi data, menyajikan data dan menarik kesimpulan.

Hasil penelitian menunjukkan perencanaan obat sesuai dengan formularium rumah sakit dan fornas, perencanaan dan pengadaan berdasarkan ROP, dalam instalasi farmasi tidak membuat RPO (Rencana Pengadaan Obat), dan tidak melakukan pengelolaan persediaan dengan cara VEN-ABC. Obat BPJS memiliki lead time lebih lama dibanding obat reguler, sehingga perhitungan ROP obat BPJS dan reguler harus terpisah. Kepatuhan dokter menulis resep sesuai fornas BPJS belum $100 \%$. Pemberian obat BPJS di rumah sakit panti wilasa citarum sesuai fornas. Direksi menentukan pemberian obat diluar fornas yang diresepkan dokter dengan mempertimbangkan apakah pasien memang membutuhkan obat tersebutdan adanya alternatif obat pengganti lain yang masuk BPJS, dan dengan melihat harga obat. Rumah sakit mengatasi perbedaan harga obat adalah dengan penghematan di bagian lain yaitu dengan mengefisienkan pengobatan, BHP, pemakaian alkes yang lebih murah.

Penelitian ini merekomendasikan beberapa saran yaitu bagi rumah sakit agar membuat RKO, melakukan perhitungan analisa VEN-ABC, membuat sistem ROP baru untuk obat BPJS, dan membuat pedoman ketetapan untuk pemberian obat pasien BPJS yang diluar fornas.

Kata kunci : perencanaan obat, pengadaan obat, pendistribusian obat, pengendalian obat, kebijakan rumah sakit

Kepustakaan : $10(1997-2015)$

\section{Abstract}

Increasing number of BPJS patients causes hospital organize the efficiency of hospital expenses for BPJS patients in order to finance hospitals to run well. BPJS drug management in Panti Wilasa Citarum Hospital Pharmacy experienced problems that causes of problem need to be analyzed and how hospital policy to overcome and how the hospital's policy in addressing the problems of BPJS drug management so the expenses do not inflated.

This study is a qualitative research with research 1 directors, 1 chief pharmacy, 1 warehouse clerk, one team of verifiers, and four people pharmacist. The research variables are planning drug, drug procurement, drug distribution, drug control and hospital policy. Analysis of the data used content analysis of data collection, data reduction, presenting the data and draw conclusions.

The results showed the drug plan in accordance with the hospital formulary and 
fornas, planning and procurement based on the ROP, the pharmacy does not make RPO (Drug Procurement Plan), and does not make VEN $A B C$ analysis. BPJS drugs have longer lead time than regular drugs, so the ROP calculation in SIM should be seperete. Compliance of physicians prescribe not $100 \%$ according to BPJS fornas. Administration of BPJS drugs in Panti Wilasa Citarum Hospital according fornas.

The Directors determines the administration of drugs outside fornas prescription to consider whether the patient is in need of that medication and any other alternative replacement drugs that enter BPJS, and by looking at the price of drugs. Hospitals overcome the differences in drug prices is with a savings treatment, consumables good for treatment, using cheaper medical devices The study recommends several suggestions are for the hospital to make $R K O$, perform calculations VEN - ABC analysis, new ROP system for BPJS drug, and establish guidelines for the provision of drug administration BPJS patients beyond fornas., create new ROP system for drug BPJS, and establish guidelines for the provision of BPJS drug administration patients that is out fornas.

Keywords : drug planning, drug precurement, drug distribution, drug control, hospital policy

Bibliography : 10 (1997-2015)

\section{Pendahuluan}

BPJS Kesehatan (Badan Penyelenggara Jaminan Sosial Kesehatan) merupakan Badan Usaha Milik Negara yang ditugaskan khusus oleh pemerintah untuk menyelenggarakan jaminan pemeliharaan kesehatan bagi seluruh rakyat Indonesia, terutama untuk Pegawai Negeri Sipil, Penerima Pensiun PNS dan TNI/POLRI, Veteran, Perintis Kemerdekaan beserta keluarganya dan Badan Usaha lainnya ataupun rakyat biasa. BPJS Kesehatan bersama BPJS Ketenagakerjaan (dahulu bernama Jamsostek) merupakan program pemerintah dalam kesatuan Jaminan Kesehatan Nasional (JKN) yang diresmikan pada tanggal 31 Desember 2013. Untuk BPJS Kesehatan mulai beroperasi sejak tanggal 1 Januari 2014. ${ }^{1}$

Instalasi Farmasi adalah unit pelaksana fungsional yang menyelenggarakan seluruh kegiatan pelayanan kefarmasian di Rumah
Sakit. Pengelolaan Sediaan Farmasi, Alat Kesehatan, dan Bahan Medis Habis pakai harus dilaksanakan secara multidisiplin, terkoordinir dan menggunakan proses yang efektif untuk menjamin kendali mutu dan kendali biaya. Pasal 15 ayat (3) UndangUndang Nomor 44 Tahun 2009 tentang Rumah Sakit menyatakan bahwa Pengelolaan Alat Kesehatan, Sediaan Farmasi, dan Bahan Medis Habis Pakai di Rumah Sakit harus dilakukan oleh Instalasi Farmasi sistem satu pintu. Alat Kesehatan yang dikelola oleh Instalasi Farmasi sistem satu pintu berupa alat medis habis pakai/peralatan non elektromedik, antara lain alat kontrasepsi (IUD), alat pacu jantung, implan, dan stent. ${ }^{2}$

Rumah Sakit Panti Wilasa Citarum Semarang merupakan Rumah Sakit yang memiliki visi dan misi dalam melayani masyarakat dibidang kesehatan dari ekonomi bawah sampai menengah dengan tidak melupakan masyarakat ekonomi atas. Rumah Sakit melaksanakan visi dan misi rumah sakit dengan mengerti pentingnya kerjasama dengan BPJS Kesehatan dalam melayani pasien. RS Panti Wilasa Citarum telah bekerja sama dengan PT ASKES maupun PT Jamsostek. Setelah ASKES dan Jamsostek menjadi satu menjadi BPJS, RS Panti Wilasa Citarum tetap meneruskan kerjasama yang dilakukan.

Rumah Sakit Panti Wilasa Citarum merupakan rumah sakit tipe $\mathrm{C}$ yang menjadi rumah sakit rujukan tingkat ke 2 pasien BPJS. Rumah Sakit Panti Wilasa Citarum melayani pasien rawat inap BPJS, pasien rujukan rawat jalan BPJS, dan pasien Hemodialisa. Dari awal berlakunya BPJS hingga akhir tahun 2015 peserta yang dirujuk dan berobat di panti wilasa citarum jumlahnya terus bertambah. Jumlah pasien BPJS rawat jalan pada bulan Januari 2014 adalah 749 (11,12\%) dan pasien umum 5984 (88,88\%), sedangkan rawat inap pasien BPJS berjumlah $67(5,41 \%)$ dan pasien umum 1172 (94,59\%). Sedangkan pada bulan Desember 2015 pasien BPJS rawat jalan adalah $6747(77,70 \%)$ dan pasien umum $1936(22,30 \%)$, sedangkan rawat inap pasien BPJS berjumlah $553(50,05 \%)$ dan pasien umum $552(49,95 \%)$. 
Rumah sakit dapat menagihkan (Klaim) paket BPJS berdasarkan paket INA CBG's dan fee for service. Untuk pasien rawat inap, dan hemodialisa klaim yang dilakukan berdasarkan paket INA CBG's. Sedangkan untuk pasien rawat jalan terpadat dua kategori penagihan. Untuk pelayanan dokter, laboratorium, radiologi, dan obat tidak kronis penagihan dilakukan sesuai paket INA CBG's. Khusus obat kronis ditagihkan terpisah sesuai dengan buku pedoman formularium nasional BPJS ditagihkan berdasarkan fee for service. Penagihan fee for service selain berdasarkan buku pedoman formularium nasional (fornas) juga berdasarkan harga e-catalog pemerintah. Tujuan utama pengaturan obat dalam Fornas adalah meningkatkan mutu pelayanan kesehatan, melalui peningkatan efektifitas dan efisiensi pengobatan sehingga tercapai penggunaan obat rasional. Bagi tenaga kesehatan, Fornas bermanfaat sebagai "acuan" bagi penulis resep, mengoptimalkan pelayanan kepada pasien, memudahkan perencanaan, dan penyediaan obat di fasilitas pelayanan kesehatan. Dengan adanya Fornas maka pasien akan mendapatkan obat terpilih yang tepat, berkhasiat, bermutu, aman dan terjangkau, sehingga akan tercapai derajat kesehatan masyarakat yang setinggi-tingginya. Oleh karena itu obat yang tercantum dalam Fornas harus dijamin ketersediaan dan keterjangkauannya. Pembelian obat dan alat kesehatan Fornas melalui e-catalog. $E$ catalog adalah sistem informasi elektronik yang memuat daftar, jenis, spesifikasi teknis dan harga barang tertentu dari berbagai Penyedia Barang/Jasa Pemerintah. Pembelian obat e-catalog adalah dengan e-purchasing dengan sistem komputer yang dipesan melalui internet. E-catalog dan e-purchasing saat ini hanya dapat dilakukan oleh fasilitas kesehatan milik pemerintah.

Instalasi Farmasi Rumah Sakit Panti Wilasa Citarum mengalami kesulitan dalam pengadaan obat BPJS yaitu e-catalog yang tidak bisa diakses rumah sakit swasta, tidak semua jenis obat yang tersedia di e-catalog dapat dibeli oleh rumah sakit dengan harga $e$ catalog karena ketersediaan obat BPJS yang terbatas, tidak semua jenis obat di fornas tersedia di e-catalog. Kesulitan dalam pengadaan obat BPJS mempengaruhi pemberian obat yang dapat diberikan oleh rumah sakit kepada pasien BPJS. Kekosongan obat BPJS mengakibatkan instalasi farmasi menunda pembelian obat yang mengakibatkan pasien BPJS rawat jalan tertunda pemberian obatnya. Sedangkan untuk rawat inap apabila obat dengan harga ecatalog tidak ada menyebabkan instalasi farmasi membeli obat dengan harga reguler yang jauh lebih mahal.

Dari wawancara yang dilakukan oleh penulis pada bulan januari 2016 dengan petugas gudang farmasi, permasalahan yang ada saat ini adalah rumah sakit mendapat obat BPJS tidak sesuai dengan harga e-catalog, proses pengiriman obat BPJS lebih lama, terjadi kekosongan obat BPJS di distributor. Sedangkan dengan bagian keuangan dan tim verifikator internal BPJS diketahui bahwa penagihan obat BPJS fee for service terdapat kendala gagal klaim karena ketidak sesuaian dengan restriksi yang diberikan oleh BPJS. Untuk permasalahan pendistribusian obat BPJS ke pasien di rawat jalan dihadapkan pada ketersediaan obat yang terbatas, sedangkan di rawat inap pada pola pengobatan pasien inap yang bervariasi dan lama pengobatan yang terkadang melebihi ekspektasi awal pengobatan. Dengan permasalahan tersebut, rumah sakit tetap dituntut untuk memberikan pelayanan terbaik untuk pasien BPJS.

\section{Metode Penelitian}

Penelitian ini dilakukan dengan metode kualitatif yang disajikan secara deskriptif. Penelitian dilakukan pada bulan Maret-Mei 2016 yang berlokasi di RS Panti Wilasa Citarum Semarang. Variabel penelitian adalah pengelolaan obat yang meliputi : 1) perencanaan obat, 2) Pengadaan Obat, 3) Pendistribusian Obat, 4) Pengendalian Obat, dan 5) KebijakanRumah Sakit. Pengumpulan data dilakukan dengan wawancara mendalam dan telaah dokumen. Subjek penelitian terdiri dari informan utama yaitu satu direksi, satu kepala instalasi farmasi, satu petugas gudang, satu tim verifikator, dan dan informan triangulasi sebanyak empat orang orang petugas farmasi. 
Selanjutnya data diolah kemudian dianalisis dengan menggunakan content analysis.

\section{Hasil}

Perencanaan Obat BPJS

Seleksi atau pemilihan jenis obat di RSPW citarum berdasarkan Formularium Rumah Sarkit dan Formularium Nasional. Metode perencanaan obat menggunakan metode konsumsi yang dilakukan seminggu sekali yang menggunakan data pemakaian sebelumnya dengan melihat ROP (repeat order) yang telah dibuat dalam SIM Rumah Sakit. Jumlah pembelian obat ditentukan berdasarkan ROP (re-order point) yang dihitung oleh sistem komputer dan Rancangan Kebutuhan Obat (RKO) BPJS juga belum pernah dibuat. Dari pengamatan dan wawancara peneliti, dalam perencanaan obat belum disertai dengan perhitungan VEN (Vital, Esensial, Non Esensial) dan ABC (parreto). Berdasarkan wawancara dengan informan utama A2 dan A4 diketahui perhitungan VEN-ABC tidak pernah dilakukan dan direksi maupun yayasan tidak pernah mengusulkan untuk dibuatnya analisa VEN-ABC.

Pengadaan Obat BPJS

Rumah sakit panti wilasa citarum melakukan pengadaan seminggu sekali pada hari rabu. Pengiriman beberapa obat BPJS lebih lama dibandingkan dengan obat reguler karena adanya prosedur yang harus dilalui. Jumlah obat BPJS yang tersedia di distributor terbatas menyebabkan jumlah obat yang dipesan dan yang diterima tidak sama. Apabila rumah sakit tidak dapat membeli obat BPJS dengan cara manual e-catalog, Instalasi Farmasi akan mencari obat dengan kandungan yang sama dengan harga yang dibeli rumah sakit bisa mendekati harga e-catalog.

Pendistribusian obat BPJS

Penditribusian obat di Panti Wilasa citarum menggunakan dua metode yaitu metode individual prescription (resep) di rawat jalan dan pada One Day Dose Dispensing (ODDD) dengan kartu obat. Semua pemberian obat pasein rawat inap dan rawat jalan berpedoman pada formularium nasional yang di dalamnya terdapat nama generik obat beserta jumlah maksimal diresepkan. Secara administratif penagihan obat di rawat inap termasuk dalam paket INA CBG's tergantung dari diagnosa pasien dirawat. Sedangkan rawat jalan terbagi menjadi dua yaitu penagihan secara paket INA CBG's dan penagihan obat kronis. Paket kronis (fee for service) hanya ditagihkan untuk 23 hari pemakaian ke BPJS, sisanya yaitu 7 hari masuk dalam INA CB'Gs paket rawat jalan. Penagihan tidak kronis juga masuk dalam paket INA CBG's dan berdasarkan ketentuan rumah sakit obat yang diberikan maksimal 7 hari.

Pengendalian Obat BPJS

Pengendalian obat BPJS dengan cara stok opnam setiap setahun sekali, pengecekan obat ED setiap 6 bulan sekali, adanya safety stock untuk menghindari terjadinya kekosongan obat, di gudang ada kartu stok yang memudahkan pengecekan keluar-masuk barang. Sedangkan untuk obat BPJS yang mengalami kekosongan, rumah sakit akan membeli obat paten lain dengan melakukan negosiasi sehingga mendapatkan harga yang didapat rumah sakit dapat sama dengan harga BPJS. Pada pelayanan rawat inap bila terjadi kekosongan obat petugas akan segera mencari obat pengganti dengan konfirmasi dan persetujuan dari wadir pelayanan untuk diberikan ke pasien. Sedangkan di rawat jalan, obat BPJS tidak kosong distributor tidak langsung diganti obat lain tetapi dengan menunda pemberian obat

Kebijakan Rumah Sakit

Kebijakan BPJS yang ada di Rumah Sakit Panti Wilasa Citarum berdasarkan kebijakan yang ada di Formularium Nasional. Hal-hal yang berkaitan dengan obat yang akan diberikan kepada pasien BPJS yang tidak ada dalam formularium nasional berdasarkan kebijakan wadir pelayanan (direksi) yang akan berbeda kebijakannya tergantung kasusnya. Rumah sakit melakukan penekanan biaya pengobatan di sektor lain agar dapat menutup kerugian

\section{Pembahasan}

Perencanaan Obat BPJS

Seleksi obat BPJS di RS Panti Wilasa Citarum menggunakan kombinasi antara 
formularium rumah sakit dan formularium nasional. Kombinasi dilakukan karena tidak semua obat yang masuk formularium nasional ada dalam formularium rumah sakit dan sebaliknya. Adanya formularium rumah sakit, diharapkan dapat meningkatkan efisiensi dan juga efektivitas pengelolaan persediaan obat mulai dari perencanaan, pengadaan, dan distribusi Fornas merupakan daftar obat terpilih yang dibutuhkan dan tersedia di fasilitas pelayanan kesehatan sebagai acuan dalam pelaksanaan JKN. Tujuan utama pengaturan obat dalam Fornas adalah meningkatkan mutu pelayanan kesehatan, melalui peningkatan efektifitas dan efisiensi pengo batan sehingga tercapai penggunaan obat rasional. Bagi tenaga kesehatan, Fornas bermanfaat sebagai "acuan" bagi penulis resep, mengoptimalkan pelayanan kepada pasien, memudahkan perencanaan, dan penyediaan obat di fasilitas pelayanan kesehatan. Dengan adanya Fornas maka pasien akan mendapatkan obat terpilih yang tepat, berkhasiat, bermutu, aman dan terjangkau.

Perencanaan di Instalasi Farmasi RSPW Citarum berdasarkan metode konsumsi yaitu dengan melihat perencanaan sebelumnya. Jumlah pembelian obat ditentukan berdasarkan ROP (re-order point) yang dihitung oleh sistem komputer. Keunggulan metode konsumsi adalah data yang diperoleh akurat, metode paling mudah, tidak memerlukan data penyakit maupun standar pengobatan. Jika data konsumsi lengkap pola penulisan tidak berubah dan kebutuhan relatif konstan maka kemungkinan kekurangan atau kelebihan obat sangat kecil. Kekurangannya antara lain tidak dapat untuk mengkaji penggunaan obat dalam perbaikan penulisan resep, kekurangan dan kelebihan obat sulit diandalkan, tidak memerlukan pencatatan data morbiditas yang baik. ${ }^{3}$

Pembuatan Rencana Kebutuhan Obat (RKO) selama setahun terutama obat BPJS juga belum dilakukan. Saat ini pemerintah dan perusahaan obat sedang berusaha mengajak rumah sakit swasta yang melayani BPJS membuat RKO obat BPJS agar perencanaan pengaanggaran jumlah obat yang dibutuhkan selama setahun di seluruh
Indonesia lebih tepat. Ketepatan perencanaan secara nasional dapat mengurangi kekosongan obat. Pembuatan RKO sebaiknya dibuat 1 tahun sebelumnya agar industri farmasi dapat melakukan persiapan dengan matang dan harga obat menjadi lebih murah. Permintaan obat yang telah dimiliki oleh pemerintah akan dilelang dengan sistem e-catalog. Dengan adanya sistem lelang dengan e-catalog harga obat bisa turun $30-40 \% .{ }^{4,5}$

Dari pengamatan dan wawancara peneliti, dalam perencanaan obat belum disertai dengan perhitungan VEN (Vital, Esensial, Non Esensial) dan ABC (parreto). Perhitunggan VEN dan ABC akan membantu dalam meningkatkan efisiensi dan efektivitas pengadaan obat berdasarkan dana yang tersedia terutama untuk obat BPJS. Berdasarkan wawancara dengan informan utama A2 dan A4 diketahui perhitungan VEN-ABC tidak pernah dilakukan dan direksi maupun yayasan tidak pernah mengusulkan untuk dibuatnya analisa VEN-ABC. Berdasarkan penelitian sebelumnya yang dilakukan oleh Lyombe, T.H. di rumah sakit Muhimbili National Hospital menunjukkan bahwa dengan tidak adanya analisis VEN dan $\mathrm{ABC}$ terjadi inefisiensi dalam mengalokasikan dana. ${ }^{6}$

Pengadaan Obat BPJS

Rumah sakit panti wilasa citarum melakukan pengadaan seminggu sekali pada hari rabu. Rumah Sakit mengharapkan dengan waktu pengadaan seminggu sekali dapat mengurangi terjadinya penumpukan dana penyimpanan obat dalam waktu yang lama. Waktu pengadaan seminggu sekali dapat mengurangi terjadinya kekosongan obat, karena apabila sebelum satu bulan obat yang sudah habis dapat dibeli kembali. Hal ini juga telah dibuktikan dengan penelitian Andhi Suyanto di Instalasi Farmasi Jala Ammari yang menmberikan hasil penggunaan metode mingguan mengurangi terjadinya kekosongan. $^{7}$

Pengadaan obat secara langsung (direct procurement), cara ini paling sederhana dibanding yang lainnya oleh karena pengelola obat melakukan pembelanjaan obat sesuai dengan yang dibutuhkan langsung kepada pemasok (PBF). Cara ini umumnya 
dilakukan bila beberapa jenis obat hanya dapat disuplai oleh satu jenis industri yang ada karena tidak ada competitor lain. Cara pengadaan langsung ini sebaiknya baru dilakukan pada keadaan tertentu seperti misalnya emergency, item obat yang dibeli sangat sedikit, atau jika karena kondisi tidak memungkinkan lagi untuk dilakukan negosiasi. ${ }^{3}$ Pengadaan secara langsung dilakukan untuk obat e-catalog yang dapat diberikan ke rumah sakit swasta dan tidak ada obat lain yang sejenis yang dapat memberikan harga diskon mendekati harga e-catalog. Rumah sakit swasta mengalami kesulitan dalam pengadaan obat BPJS pada karena tidak dapat masuk dalam sistem pengadaan obat e-catalog. Obat BPJS yang tidak dapat dibeli secara e-catalog menyebabkan adanya selisih harga obat yang dibeli dan obat yang dapat ditagihkan.

Saat ini ARSSI telah mengungkapkan dan memperjuangkan rumah sakit swasta untuk dapat mengaskses e-catalog dan epurchasing. Keuntungan dari pembelian obat dan AlKes dengan e-catalog adalah terjaminnya kualitas obat dan AlKes untuk keselamatan pasien dan keuntungan harga yang lebih murah sehingga rumah sakit swasta dapat mengendalikan mutu dan biaya pengobatan pasien.

Pendistribusian obat BPJS

Metode pemberian obat BPJS tidak berbeda dengan pemberian pada pasien umum. Individual prescription merupakan pendistribusian obat langsung diterima oleh pasien sesuai dengan resep yang diberikan. Sedangkan ODDD merupakan pendistribusian yang dilakukan dengan mempersiapkan dosis dalam satu hari. Berdasarkan penelitian yang dilakukan Erna Yanti pada tesis Evaluasi Penerepan Sistem Kartu Obat Rawat Inap pada One Day Dose Dispensing (ODDD) Terhadap Pola Penggunaan Obat dan Biaya Obat Pasien BPJS Hipertensi di RSUD Liwa membuktikan pola penggunaan ODDD meningkatkan pola penggunaan obat meningkat dan biaya obat menurun. ${ }^{8}$

Dari data penagihan INA-CBG's RSPW Citarum tidak banyak mengalami banyak kendala, tetapi pada penagihan fee for service masih belum dapat tertagihkan. Pada tahun 2014 dan 2015 masih terdapat penagihan obat yang terpending, sehingga penagihan fee for service BPJS untuk tahun 2016 belum dapat ditagihkan. Penagihan obat yang terpending disebabkan karena petugas yang mengalami kesulitan dalam menginput nama obat yang diberikan kepada pasien BPJS karena adanya perbedaan nama obat yang tersedia di rumah sakit dengan nama obat di e-catalog, kurangnya data penunjang yang diminta BPJS, dan kesalahan pemberian obat kronis karena petugas farmasi kurang menguasai pedoman fornas BPJS. Awal dibentuknya tim verifikator, Rumah sakit belum menunjuk apoteker sebagai bagian dari tim verifikator sehingga saat penagihan obat dengan nama yang berbeda dengan e-catalog tidak dapat tertagihkan. Awal tahun 2016 rumah sakit telah menunjuk satu apoteker yang bertugas sebagai tim verifikator internal BPJS diharapkan dapat menyelesaikan pending obat secara fee for service. Instalasi Farmasi RSPWC selalu melakukan update dan melakukan sosialisasi kepada petugas instalasi farmasi mengenai fornas BPJS, perubahan peraturan internal Rumah Sakit, dan perubahan peraturan dari BPJS untuk meminimalkan kesalahan pemberian obat BPJS.

Pengendalian Obat BPJS

Pengendalian obat BPJS tidak berbeda dengan obat reguler. Apabila terjadi kekorsongan obat BPJS, rumah sakit akan membeli obat paten lain dengan melakukan negosiasi sehingga mendapatkan harga yang didapat rumah sakit dapat sama dengan harga BPJS.

Pengendalian persediaan juga dapat diartikan sebagai serangkaian kebijakan pengendalian untuk menentukan tingkat persediaan yang harus dijaga, kapan pesanan untuk menambah persediaan harus dilakukan dan berapa besar pesanan harus diadakan. Pengendalian persediaan menentukan dan menjamin tersedianya persediaan yang tepat dalam kuantitas dan waktu yang tepat. ${ }^{9}$ Perhitungan ROP obat BPJS berbeda dengan reguler karena lead time yang terkadang melebihi lead time obat reguler dan menyebabkan stok yang ada di pelayanan kurang dari safety stock. Pada pelayanan 
rawat inap bila terjadi kekosongan obat petugas akan segera mencari obat pengganti dengan konfirmasi dan persetujuan dari wadir pelayanan untuk diberikan ke pasien. Sedangkan di rawat jalan, obat BPJS tidak kosong distributor tidak langsung diganti obat lain tetapi dengan menunda pemberian obat

Tim verifikator internal BPJS memiliki fungsi dalam pengendalian obat BPJS. Tim verifikator internal BPJS berfungsi sebagai petugas yang akan memverifikasi kesesuian harga, jenis, merk dan jumlah obat yang diberikan ke pasien BPJS. Selain itu, fungsi dari tim verifikator adalah melakukan verifikasi administrasi kepersertaan, verifikasi administrasi pelayanan, dan verifikasi pelayanan pada pasien BPJS. Dengan adanya tim verifikator BPJS internal, petugas di pelayanan dapat melakukan pelayanan sesuai dengan prosedur yang ditetapkan BPJS.

Kepatuhan dokter menulis resep BPJS sesuai dengan fornas BPJS belum 100\%. Dokter masih memberikan resep obat tidak ada dalam fornas, tidak sesuai restriksi, dan jumlah pemberian tidak sesuai. Rumah sakit telah beberapa kali melakukan pertemuan rutin dengan dokter tetap maupun mitra untuk membahas mengenai pasien BPJS, tetapi masih ada dokter yang memberikan resep tidak sesuai dengan ketentuan fornas. Ketidaksesuaian pemberian obat ke pasien BPJS menyebabkan petugas instalasi farmasi harus melakukan konfirmasi ulang ke dokter atau direksi untuk pemberian obat menyebabkan pelayanan pemberian obat ke pasien BPJS menjadi lama. Tidak adanya peraturan atau pedoman tertulis untuk pemberian obat pasien BPJS diluar fornas menyebaban masih banyak dokter yang menulis obat tidak sesuai ketentuan fornas.

Kebijakan Rumah Sakit

Direksi menentukan pemberian obat diluar fornas BPJS karena obat memang harus diberikan dan tidak ada obat pengganti lain, dan dilihat dari harga obat yang akan diberikan. Rumah Sakit Pant Wilasa Citarum merupakan rumah sakit swasta sehingga tidak memiliki akses e-catalog obat BPJS tetapi masih bisa mengakses obat BPJS dengan cara manual. Harga obat yang diberikan oleh distributor untuk obat BPJS di rumah sakit swasta tidak semua sesuai dengan harga $e$ catalog. Berdasarkan wawancara dengan direksi dan data yang didapat, diketahui pembayaran fee for service (untuk obat kronis) BPJS yang menyebabkan rumah sakit mengalami kerugian dari selisih penagihan. Rumah sakit mengatasi perbedaan harga obat adalah dengan penghematan di bagian lain yaitu dengan mengefisienkan pengobatan, BHP, pemakaian alkes yang lebih murah. Berdasarkan penelitian dari Prof. dr. Iwan Dwiprahasto, MMedSc, $\mathrm{PhD}$, penghematan tarif INA CBG's dapat di sektor obat, diagnosis, BMHP dan bagian yang tidak bisa dihemat adalah tindakan, kamar, jasa medik. Penghematan di sektor obat INA CBG's berdasarkan penelitian dapat dilakukan dengan mengoptimalkan penerapan Fornas sebagai acuan dalam perencanaan dan penyediaan obat di fasilitas kesehatan dan meningkatkan peran tenaga kesehatan dalam melakukan pemantauan penggunaan obat dalam sistem JKN berdasarkan Fornas. ${ }^{10}$

\section{Kesimpulan}

Perencanaan obat BPJS di Rumah Sakit Panti Wilasa Citarum berdasarkan formularium rumah sakit dan fornas (Formulariun Nasional), dilakukan oleh kepala instalasi farmasi setiap minggu berdasarkan metode konsumsi dengan melihat ROP. Rumah sakit belum melakukan perhitungan Perencanaan Rencana Kebutuhan Obat (RKO) BPJS selama setahun dan belum melakukan analisa VEN-ABC untuk mengefisienkan alokasi dana untuk pembelian obat, terutama obat BPJS.

Pengadaan obat BPJS diakukan seminggu sekali berdasarkan ROP untuk mengurangi penumpukan dana penyimpanan obat. Pembelian obat BPJS dengan metode negosiasi dan pengadaan obat e-catalog secara manual. Tidak semua obat e-catalog dapat diakses oleh rumah sakit karena ketidaktersedian obat BPJS di PBF. Kekosongan obat menyebabkan rumah sakit membeli obat dari pabrikan lain dengan harga lebih mahal.

Pendistribusian obat BPJS: sesuai dengan Good Pharmacy Practice yaitu Rawat inap dengan One Day Dose Dispensing 
dan Rawat jalan dengan Individual prescription. Penagihan dan pemberian obat Rawat inap sesuai dengan tarif paket INA CBG's. Penagihan dan pemberian obat rawat jalan terbagi menjadi paket INA CBG's dan penagihan obat kronis 23 hari masuk dalam penagihan fee for service. Pemberian obat BPJS di rumah sakit panti wilasa citarum berdasarkan pedoman fornas.

Pengendalian obat BPJS hampir sama dengan obat reguler, tetapi karena kekosongan distributor lebih sering terjadi dibanding obat reguler yang menyebabkan perhitungan lead time dan ROP berbeda sehingga harus dibuat perhitungan pengadaan obat yang terpisah antara obat reguler dan BPJS. Kekosongan obat di distributor di rawat jalan dan rawat inap diatasi dengan mengganti obat dengan paten lain dengan harga mendekati harga ecatalog. Kekosongan obat di rawat jalan karena keterlambatan pengiriman diatasi dengan penundaan pemberian obat pasein. Kepatuhan dokter menulis resep BPJS sesuai dengan fornas BPJS belum $100 \%$.

Kebijakan rumah sakit dalam mengatasi perbedaan harga obat adalah dengan penghematan di bagian lain yaitu dengan mengefisienkan pengobatan, BHP, pemakaian alkes yang lebih murah. Kebijakan rumah sakit dalam menentukan pemberian obat BPJS diluar fornas ditentukan oleh direksi dengan mempertimbangkan apakah pasien memang membutuhkan obat tersebut dan adanya alternatif obat pengganti lain yang masuk BPJS, dan melihat harga obat.

\section{Daftar Pustaka}

1. BPJS. Pedoman Umum Tata Kelola yang Baik BPJS Kesehatan. 2014

2. Depkes RI. Permenkes Nomor 58 Tahun 2014 tentang Standar Pelayanan Kefarmasian di Rumah Sakit. 2014

3. KepMenKes RI No. 1197/Menkes/SK/2004. Standar Pelayanan Rumah Sakit.

4. Dirjen Bina Kefarmasian dan alat Kesehatan. Jaminan Kesehatan dan Ketersediaan Obat. Infarkes buletin edisi II maret-Mei 2015

5. Lyombe, T.H., Analysis of Medicines Expenditures and Pharmaceutical Inventory Control Management at Muhimbili National Hospital (Disertasi). 2013.

6. Quick D. Jonathan. Managing Drug Supply (2nded). Management Sciences for Health. USA: Kumarian Press; 1997

7. Dirjen Bina Kefarmasian dan alat Kesehatan. Kebijakan Kefarmasian dan Alkes di Era JKN menurut UU no 23 tahun 2014. Pertemuan Policy Dialogue Jakarta, 5 Mei 2015.

8. Djasri, Hanevi. Peran Clinical Pathways dalam Sistem Jaminan Sosial Nasional Bidang Kesehatan. Workshop INA-CBG, diselenggarakan IMRS-PERSI, 3-4 Juli 2013.

9. Dirjen Bina Kefarmasian dan alat Kesehatan. Pedoman Pelayanan Farmasi yang Baik. 2011

10. Anief, Moh. Manajemen Administrasi Rumah Sakit. Jakarta: Universitas Indonesia Press; 2003. 